\section{La Era de la Crónica}

Marcela Aguilar Guzmán. (2019).

La Era de la Crónica. Santiago, Chile: Ediciones UC. 175 páginas. ISBN 978-956-14-2436-4

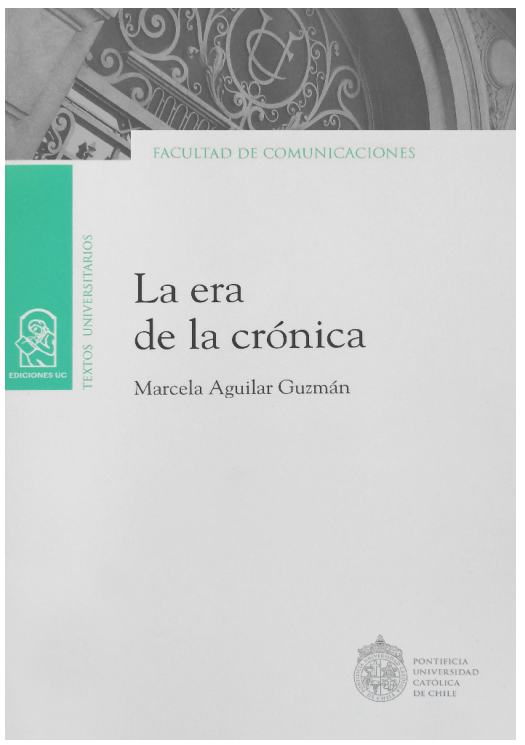

¿Qué es el tiempo? ¿Cuál es la brecha? ¿Ficción o realidad? ¿Hasta dónde llegan las palabras? ¿Acaso las historias conmueven, mueven, presionan, pueden desestabilizar al poder, a la arrogancia, descubrir fronteras, crear otras? ¿Hasta dónde llegan las palabras? A medida que se avanza en la lectura de este libro, es imposible dejar de escuchar a ese moscardón del que hablaba Javier Darío Restrepo, maestro de la Fundación Nuevo Periodismo Iberoamericano (hoy Fundación Gabo). Ese moscardón y su zumbido cubierto de letras y acciones arriesgadas, investigación, ética puesta a prueba, algo de épica y algo de fracaso. Susana Rotker reaparece de igual forma en cada página, porque lo que Aguilar hace es retomar un hilo que, luego de la muerte de la autora venezolana, fue arrancado de cuajo (La invención de la crónica, 1992).

Es así como esta lectura se cruza con cronistas de Indias y, en paralelo, con cronistas de la modernidad que intentaron narrar esta otra América, como José Martí o Rubén Darío. Y de ahí a Alma Guillermoprieto, Carlos Monsiváis, Elena Poniatowska, por nombrar sólo a tres que, desde México, nos contaron parte clave para comprendernos como América Latina. La Era de la Crónica de Marcela Aguilar se funda en historias y espacios biográficos de autores y autoras de un tiempo presente, posible de reconocer en las vidas "invivibles" que en él se vuelcan o en el vivir bien que, oteando entre retazos, aparece en las fronteras del poder.

Textos y contextos se mueven con Aguilar desde un lugar pendular en que la construcción de la subjetividad latinoamericana, especialmente, que aquí aparece, pareciera generar un acto performativo al enfrentarse a las innumerables condicionantes sociales, históricas y culturales que presionan sobre quiénes escriben y sobre quiénes se escribe. Este estudio no agrega más capas al análisis, sino, más bien, se aboca a intentar destrabar la madeja que implica hacer literatura desde el periodismo. Y lo hace con precisión quirúrgica, sin comprometer en demasía un punto de vista político agudo sobre las representaciones y sus implicancias. El libro actúa, por tanto, a modo de cartografía extendida sobre una tabla rasa que presume continentes profundos en los que cada punto en el mapa arroja una autoría y una escala propia.

Desde la introducción, los objetivos son claros porque lo que se observa es una estrategia para desterrar la idea de que la crónica pertenece a un género menor. Por consiguiente, es una fórmula, una práctica, una rutina, una forma de vida para contar historias. Serán los relatos de la larga Historia, ésa de revueltas, abandonos, esperanzas a fuego, ciudades distópicas, puntos de fuga, ovaciones al poder y desacatos al poder. Junto con lo anterior, la autora plantea la búsqueda del acontecimiento que permita una historicidad entre ensayos, prólogos, columnas y entrevistas.

Tanto se ha escrito sobre la crónica durante estos últimos años lno al nivel de Rotker, tal vez), que Aguilar busca pistas para su propia escala de mapas, articulando estas reflexiones con la materialidad discursiva que aquí aparece en tanto cuerpos, divergencias, destierros, fiestas populares, crímenes, retos políticos y sobre “la política”, y escritos en prosa. La polis y las formas de habitarlas son una constante en esta industria cultural, que revistas como la peruana Etiqueta Negra (suspendida por ahora) y otras, han marcado como señales de un tiempo. “ ¿Tiene, entonces, algún sello distintivo la llamada nueva crónica latinoamericana? ¿0 su visibilidad mediática se debió más bien a un ejercicio ajeno al texto mismo?" (p.18), se pregunta Aguilar, para continuar introduciendo en esta lectura a letrados/as y a quienes solo han mirado de reojo las páginas de tinta y alambiques digitales que hay detrás de Leila Guerriero, Martín Caparrós, Alberto Salcedo Ramos, Josefina Licitra, Juan Pablo Meneses, Gabriela Wiener, Julio Villanueva Chang, Cristian Alarcón, Juan Villoro, Daniel Titinger, Alberto Fuguet, Juan Cristóbal Peña, Marcela Turati y Rodrigo Fluxá. Ellos/as son los hitos en la cartografía, quedando afuera decenas de otras voces que, quizás más alejadas del centro, se instalan en derroteros de menor fama mediática. 
En el primer capítulo, Aguilar establece un punto de partida histórico, rápido, pero de múltiples niveles, produciéndose un movimiento especial entre crónica de Indias, crónica de la conquista, del siglo XIX y XX y la actual, vinculada al Nuevo Periodismo estadounidense, al periodismo literario latinoamericano y a sus espacios de producción Imedios como El Faro - Anfibia son fundamentales, como lo son, también, la Fundación Gabo - ¿el nuevo, pero fallido, boom?-, The New Yorker o Gatopardol, circulación y consumo laudiencias dispersas, fragmentadas y neoliberales).

A propósito, la autora establece que, en la actualidad,

es difícil definir la crónica latinoamericana, ya que se ha disgregado en múltiples líneas, desde la más contemplativa, como la de Roberto Merino o Francisco Mouat en Chile, hasta la investigación periodística, que desarroIlan en Chile Juan Cristóbal Peña - Javier Rebolledo. Si la crónica modernista se define en importante medida por el soporte: el periódico y la revista (dos medios impresos que alcanzaron enorme circulación e influencia en la primera mitad del siglo XX), la crónica contemporánea se publica en escasos medios impresos que, además, han perdido circulación e influencia desde que la información comenzó a circular libremente en plataformas digitales (p.37).

“¿Quién habla y cómo habla en la crónica?" se titula el segundo capítulo, un espacio central que seguro agradecen los y las estudiantes de periodismo, porque se vuelve una especie de manual que disecciona fragmentos para dar con los tiempos lla música se emparenta con la disposición de las palabras), el punto de vista y el proceso de construcción, donde las voces son esqueleto y forma. La metodología de análisis textual sostiene la tesis sobre la que se encuadra este estudio. Y es que, como se menciona, “es la dimensión dialógica de textos, enunciada por Bajtín en 1956: ninguna crónica se escribe en el vacío, cada crónica responde a un texto anterior y es posible reconocer ese diálogo, aunque haya décadas o incluso siglos de distancia entre un enunciado y otro, entre una pregunta y una respuesta". Notable Bajtín y buen rescate de Aguilar.

“De qué habla la crónica”. Así arranca el tercer capítulo. Es, tal vez, el eje central del libro, porque aquí la literatura permite cavar un foso en cada punto del mapa para llegar a los motivos (según Frenzel). Las aproximaciones se dan a partir de retazos de relatos y los hallazgos no dejan de ser interesantes, sobre todo porque el adentro es el afuera y el afuera es el adentro llo público y lo privado en una tensión con grados de humor, sarcasmo, afectos, estructuras para rastrear lo emergente, dominante, residual que cabe en el presente). No hay retórica y falta profundizar en el poder y lo político, lo invivible, en este examen a "Amazonas y heroínas"; "Añoranza de países lejanos"; "Arcadia y el salvaje noble”; “Bajada al infierno"; "Bandido justo, rebelde"; "Codicia, avaricia; sed de oro, avidez de dinero"; “Emigrante, emigración, ídolo lejano recuperado"; “Ermitaño, estrafalario"; “Tiranía, tiranicidio, traidor"; "Vida deseada y maldita en una isla". Motivos que no dejarían espacio a la radicalidad y a la ruptura.

Y es ahí donde la pregunta sobre la historicidad se vuelve a abrir para dar paso al cuarto capítulo: “Qué hablan sobre la crónica". La hibridez IVilloro la llama el "ornitorrinco de la prosa") es central en el análisis de quienes escudriñamos la crónica; y, también, lo es el concepto de "verdad", porque no hay cabida al oportunismo, como bien lo muestra Aguilar al citar a Rosanna Reguillo, porque en ella sí hay radicalidad cuando se trata de analizar ciertos textos con el prisma de la resistencia a la domesticación. En este capítulo la autora muestra el mapa de quienes analizan los textos como si fueran lugares espectrales donde habita el discurso hegemónico o aquel que esgrime el "paradigma del conflicto", apareciendo la "verdad" testimonial de la opresión como lugar central del montaje de imágenes que, a modo de collage, imprime formas estalladas de acceder al conocimiento y a estructuras del sentimiento fuera del lugar común normado por el centro y enlos márgenes de la vida cotidiana.

Por último, y siguiendo con la estructura de una tesis, la autora nos lleva a las conclusiones a través del quinto capítulo: “De qué hablamos cuando hablamos de crónica luna reflexión sobre los géneros)". Como un epílogo, esta última parte se articula desde los estudios culturales y hay mayor densidad en el análisis propio, lo que da sentido a los pasos seguidos desde el panorama, el manual, la tesis. Es una especie de marco teórico al revés, con autores como Todorov, Bajtín, Verón, Tesche y Foucault, sosteniendo un diálogo con la materialidad que le antecede. Un marco de interpretación necesario para reinstalar a la crónica como un lugar en el que, como en otros, se disputa el mundo de los sentidos.

\section{Dra. Ximena Póo F.}

Universidad de Chile xpooduchile.cl 